Original Research Article

\title{
A Study of awareness, attitude and practice of pharmacovigilance among health care professionals in a tertiary care teaching hospital in Bareilly, India
}

\author{
Krishna Singh ${ }^{1}$, Kauser Sayedda ${ }^{1 *}$, Richa Bhardwaj', Neha $\operatorname{Yadav}^{1}$, Quazi Shahir Ahmed ${ }^{2}$
}

${ }^{1}$ Department of Pharmacology, Shri Ram Murti Smarak Institute of Medical Sciences (SRMSIMS), Bareilly, Uttar Pradesh, India

${ }^{2}$ Department of Pharmacology, IIM and R, Lucknow, Uttar Pradesh, India

Received: 08 May 2017 Accepted: 02 June 2017

*Correspondence to:

Dr. Kauser Sayedda,

Email: ksayedda96@gmail.com

Copyright: () the author(s), publisher and licensee Medip Academy. This is an openaccess article distributed under the terms of the Creative Commons Attribution NonCommercial License, which permits unrestricted noncommercial use, distribution, and reproduction in any medium, provided the original work is properly cited.

\begin{abstract}
Background: Awareness towards Pharmacovigilance among health professionals in any hospital is an important part of health care system. So, the present study was conducted to know the extent of awareness of Pharmacovigilance among health care professionals.

Methods: A cross-sectional questionnaire based study about knowledge, attitude and practices towards adverse drugs reaction (ADRs) and Pharmacovigilance was carried out at Shri Ram Murti Smarak Institue of Medical Sciences, Bareilly (U.P). 153 questionnaires were distributed among the Post graduate students, faculties, interns, nurses and pharmacists. 2-3 days time was given to fill the questionnaire.

Results: Out of 153 questionnaires distributed, 99 filled forms were turned up for evaluation. Hence, response rate was $64.70 \%$. $73.33 \%$ PGs, $100 \%$ faculty members, $53.33 \%$ interns, $36 \%$ nurses and $18.75 \%$ pharmacists were aware of adverse drugs reactions (ADRs) and Pharmacovigilance. Regarding reporting of ADRs, $86.66 \%$ PGs, $91.66 \%$ faculties, $73.33 \%$ interns, $88 \%$ nurses and $81.25 \%$ pharmacists were agreed to report $\mathrm{ADR}$ as it is mandatory and related to increased patients' safety. Regarding discouraging factors for practice of reporting ADRs, 20\% PGs, $16.66 \%$ faculties, $80 \%$ interns, $40 \%$ nurses and $68.75 \%$ pharmacists found ADR forms difficult to be filled. According to $66 \%$ faculties, $80 \%$ PGs, $66.66 \%$ interns managing patients are more important than reporting ADRs while $93.75 \%$ nurses and $76 \%$ pharmacists did not know how to report and where to report.

Conclusions: The results of our study indicate that the acceptable number of health-care professionals had a good knowledge and attitude towards pharmacovigilance. There was a huge gap between the ADR experienced, and ADR reported by the health-care professionals. So, there is need of conductance of CMEs, workshops and seminars related to pharmacovigilance for all heaith care professionals especially nurses and pharmacists so, that whole community can be benefitted.
\end{abstract}

Keywords: Attitude, Health care professional, Knowledge, Practices (KAP), Pharmacovigilance

\section{INTRODUCTION}

Safety and efficacy are the two major concerns about a drug. The efficacy of a drug can be quantified with relative ease; the same cannot be said about safety. This is because, the adverse effect of a drug may be uncommon (but very serious), and many patients may be affected or subjected to a potential risk before the relationship with the drug is established. ${ }^{1}$
Despite the importance of medicine in the prevention and curing of diseases, its usage is usually associated with undesirable adverse reactions and sometimes fatal reactions. The global interest in the monitoring of drug safety showed a remarkable increase in the last four decades especially after the thalidomide disaster in the sixties. The thalidomide disaster opened up the issue of drug safety for the public and healthcare professionals alike and brought about an awareness of the importance 
of the systemic surveillance of drugs for Adverse Drug Reactions (ADRs). ${ }^{2}$

Adverse drug reaction (ADR) is defined by the World Health Organization (WHO) as "a response to a drug which is noxious and unintended, and which occurs at doses normally used in man for prophylaxis, diagnosis, or therapy of disease or for the modification of physiologic function."

Adverse drug reactions are an imperative public health crisis striking a substantial fiscal burden on the society and health-care systems. It is one of the significant bases of hospitalization varying between $5 \%$ and $20 \%{ }^{3}$ Furthermore, according to Uppsala Monitoring Centre (WHO), Sweden; which maintains the international database of the ADR reports, only 6-10\% of all the ADRs are reported. ${ }^{4}$ Hence, the detection, recording, and reporting of ADRs becomes vital and health experts should be encouraged to execute this appropriately to ensure safer usage of medicines. For this purpose, the concept of pharmacovigilance has been taken place. World Health Organization defines pharmacovigilance as "the science and activities relating to the detection, assessment, understanding, and prevention of adverse effects or any other medicine-related problems." 5

In an effort to strengthen the pharmacovigilance in India, government has initiated pharmacovigilance programme of India (PvPI). Similarly, the Drug Controller General of India and Indian Council of Medical Research have established ADR monitoring centers in many hospitals in major cities of India. ${ }^{6}$ Despite these efforts and the presence of a large number of tertiary care facilities, pharmacovigilance is still in its infancy. The major reason behind this is poor understanding of the healthcare professionals toward the existing pharmacovigilance program.

Healthcare professionals are one of the important pillars of an efficient pharmacovigilance system because of their contribution in the form of spontaneous reporting. Spontaneous reporting of ADRs is one method of Pharmacovigilance and which is undertaken through the Yellow Card Scheme (YCS) in UK. ${ }^{7}$ The Uppsala Monitoring Centre (UMC, WHO), Sweden is maintaining the international database of ADR reports. ${ }^{8}$ In India, it is maintained by Central Drugs Standard Control Organization (CDSCO) with the Drug Controller General(India) [DCG(I)] as its head. Gross underreporting of ADRs is a matter of concern in India, reasons may be lack of trained staff and lack of awareness regarding detection, communication and spontaneous monitoring of ADRs among the health-care professionals (physicians, nurses, pharmacists and dentists)

Therefore, the present study was contemplated and done to assess the knowledge, attitude, and practices (KAPs) of the health-care professionals working in a teaching hospital (institution) located in Central India region regarding ADRs reporting, to get an insight into the reasons for nonreporting and to suggest possible ways of improving spontaneous reporting based on our findings.

\section{METHODS}

\section{Study design and settings}

It was a cross-sectional, questionnaire based study about knowledge, attitude and practices towards adverse drugs reaction (ADRs) and Pharmacovigilance among Healthcare Professionals In this study, post graduate students, faculty members, interns, pharmacists and nurses were included. The study was carried out at Shri Ram Murti Smarak Institue of Medical Sciences, a tertiary care teaching hospital, Bareilly (U.P).

The study was conducted for a period of 2 months from December 2016 to January 2017.

\section{Inclusion and exclusion criteria}

There were no inclusion criteria. All health care professionals (153) who came in contact were included. The only exclusion criterion was non willingness to be included in the study.

\section{Design of Knowledge Attitude and Practice (KAP) questionnaire}

The questionnaire was a 21 items inventory titled Standard KAP Questionnaire. The items were generated from the literature and adaptation from previous studies.

\section{Assessment and structure of a questionnaire}

To assess the knowledge of pharmacovigilance, attitudes toward pharmacovigilance, and practice of ADR reporting of health-care professionals, a predesigned structured, 21 item questionnaires, typed in English language, which had been designed based on the primary objective of the study was used. To design a questionnaire, earlier studies for assessing KAP of ADR reporting were also reviewed.

The details of the questionnaire are as follows:

- Knowledge-related questions: The assessment of participant's knowledge of pharmacovigilance included six questions (items) on definition and purpose of pharmacovigilance, existence of PvPI, responsibility of reporting ADRs, knowledge of yellow card, about international center for ADR monitoring, and regulatory body responsible for monitoring ADRs.

- Attitude-related questions: The assessment of participant's attitudes toward pharmacovigilance included five questions (items) on the necessity and compulsion of reporting ADRs, teaching of 
pharmacovigilance, opinion on increase patient safety and complexity to fill ADR form in India.

- Practice-related questions: The assessment of participant's practice of ADR reporting included seven questions (items) on experience of ADRs, report to pharmacovigilance centre, ADR reporting form, training to report ADRs, reporting of serious adverse event, methods to monitor ADRs of new drug, presence of Pharmacovigilance Committee in Institute. One question was asked to determine the reasons for underreporting. That is, factors discouraging from reporting ADRs.

\section{Study conduct}

Every healthcare professional was given one to two days of time to fill the questionnaire. During attempting the questionnaire, any clarification regarding understanding of the questions was provided.

\section{Analysis of data}

Completed questionnaires were collected from each participant to evaluate the awareness of pharmacovigilance, knowledge and ADRs reporting among healthcare professionals. The filled questionnaires were analyzed with the help of Microsoft Excel worksheet (Microsoft Office 2007). Data was presented as a percent $(\%)$ of the respondents. In case of unanswered questions, the participant was excluded from the study.

\section{RESULTS}

Out of 153 questionnaires distributed, 99 filled forms were included for evaluation. Hence response rate was $64.70 \%$. Post graduate students (PGs) $(n=30)$, faculty members $(n=12)$, interns $(n=15)$, nurses $(n=25)$ and pharmacists $(n=17)$ participated in the study (Figure 1).

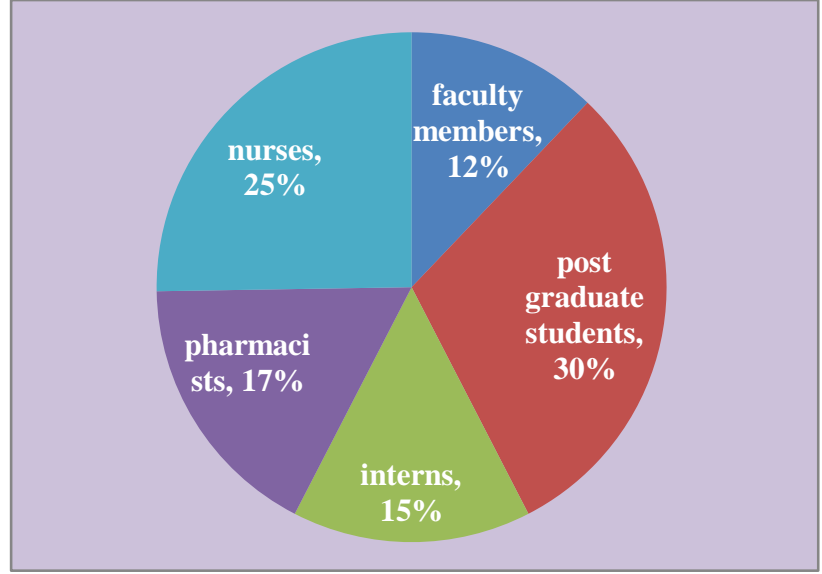

Figure 1: No. of respondents participated in the study.

The most of the health-care professionals were males, i.e. $53.53 \%$ compared to $46.46 \%$ females. Furthermore, the mean age of the study participants was 31.32 years

\section{Assessment of pharmacovigilance related knowledge}

While assessing the knowledge of the health-care professionals on pharmacovigilance, $52.94 \%$ health-care professionals quoted 'safety of the drug' as most important purpose of pharmacovigilance. Regarding this faculty members constituted highest percentage $(83.33 \%)$.

Regarding knowledge of yellow card ADR reporting form only $22.33 \%$ health-care professionals knew about that. Similarly, $37.89 \%$ of health-care professionals were aware of existence of PvPI and only $43.73 \%$ health-care professionals were aware that the regulatory body responsible for monitoring ADRs in India is Center Drug Standard Control Organisation (CDSCO) and UPPSALA (Sweden) is the international center for adverse drug reaction monitoring (Table 1$)$.

Table 1: Positive response of knowledge based questions.

\begin{tabular}{|c|c|c|c|c|c|c|c|}
\hline $\begin{array}{l}\text { S. } \\
\text { no }\end{array}$ & Knowledge based Questions & Correct answer & $\begin{array}{l}\text { Faculty } \\
\text { members }\end{array}$ & PGs & Interns & Pharmacists & Nurses \\
\hline 01 & Purpose of pharmacovigilance & $\begin{array}{l}\text { Identify the safety } \\
\text { of the drug }\end{array}$ & $83.33 \%$ & $73.33 \%$ & $53.33 \%$ & $18.75 \%$ & $36 \%$ \\
\hline 02 & $\begin{array}{l}\text { Are you aware about yellow } \\
\text { card ADR reporting form? }\end{array}$ & Yes & $41.66 \%$ & $20 \%$ & $13.33 \%$ & $11.76 \%$ & $25 \%$ \\
\hline 03 & $\begin{array}{l}\text { Are you aware of existence of } \\
\text { NPC in india? }\end{array}$ & Yes & $52.33 \%$ & $46.66 \%$ & $38.38 \%$ & $18.75 \%$ & $33.33 \%$ \\
\hline 04 & $\begin{array}{l}\text { Which regulatory body } \\
\text { responsible for monitoring } \\
\text { ADRs in india. }\end{array}$ & $\mathrm{CDSCO}$ & $83.33 \%$ & $60 \%$ & $26 \%$ & $20 \%$ & $29.41 \%$ \\
\hline 05 & $\begin{array}{l}\text { The international center for } \\
\text { adverse drug reaction } \\
\text { monitoring is located. }\end{array}$ & $\begin{array}{l}\text { UPPSALA } \\
\text { (Sweden) }\end{array}$ & $83.33 \%$ & $60 \%$ & $26 \%$ & $20 \%$ & $29.41 \%$ \\
\hline
\end{tabular}

The table shows highest percentage is of faculty members have knowledge about pharmacovigilance followed by PGs and pharmacists are having least knowledge. 


\section{Assessment of pharmacovigilance-related attitude}

While assessing the pharmacovigilance related attitude of the health-care professionals, $84.18 \%$ of health-care professionals agreed that reporting of the ADR should be necessary, mandatory and related to increase patient safety.

Overall, $91.84 \%$ health-care professionals were of the view that pharmacovigilance should be taught in detail to all health-care professionals. Furthermore, $40.56 \%$ health-care professionals agreed that ADR form is complex to fill (Figure 2).

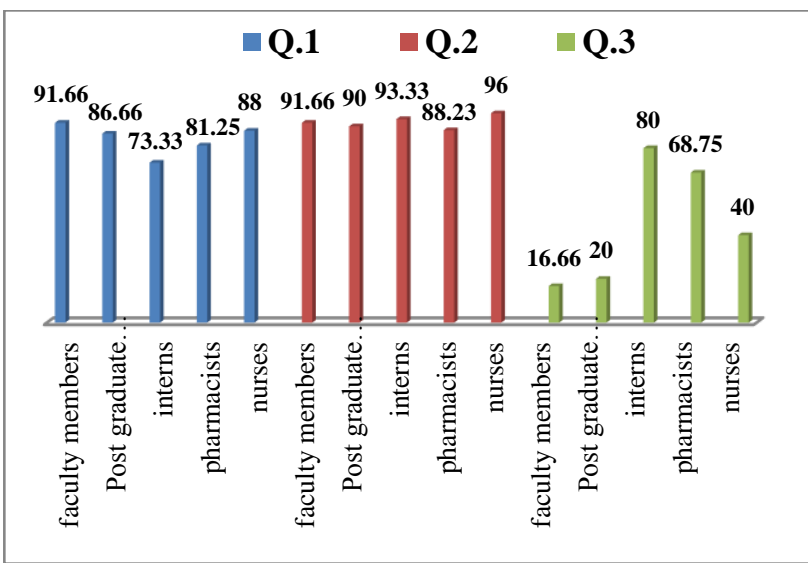

Q 1: Do you think reporting of adverse drug reaction is necessary, mandatory and related to increase patient safety (highest in faculty members).

Q 2: Do you think pharmacovigilance should be taught in detail to healthcare professionals (highest in nurses).

Q 3: ADR form is complex to fill (highest in interns).

Figure 2: Positive response of attitude based question.

Assessment of pharmacovigilance-related practices

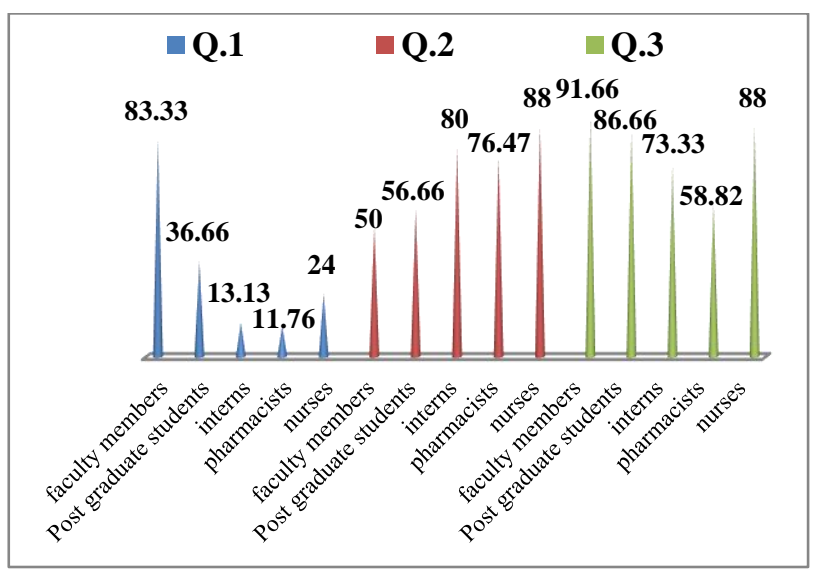

Q. 1: Have you ever been trained on how to report adverse drug reaction (highest in faculty members).

Q. 2: Did not know how to report and where to report (highest in nurses).

Q. 3: Managing patient are more important than reporting ADRs (highest in faculty members).

Figure 3: Response of practices related question.
On assessing the pharmacovigilance-related practices, only $49.04 \%$ of health-care professionals experienced ADRs in patients during their professional life and very few health-care professionals i.e. 6.12\% (highest among them is faculty members i.e. $16.66 \%$ ) have ever reported ADR to monitoring system to pharmacology department, then thru department ADR forms are scanned and mailed to regional ADR monitoring center. None of the PGs, interns, pharmacists and nursing professionals have reported the ADRs.

Further, it was found that only $33.81 \%$ health-care professionals have been trained on reporting on ADR (Figure 3). About discouraging factors, lack of knowledge regarding ADR reporting 76.47\% pharmacists and $88 \%$ nursing professionals did not know how to report and where to report. According to $91.66 \%$ faculty members, more emphasis should be given to managing the patient rather than reporting ADR (Figure 3).

\section{DISCUSSION}

During the developmental phase of a drug, a good deal is known about its therapeutic activity but rather less about its safety because the clinical trials are conducted in a controlled environment in a lesser number of patients and subjects. Once a drug gains entry into the market, it will be prescribed by hundreds of doctors to thousands of patients belonging to different age groups. The scenario is complicated when there are ethnic variations, presence of co-morbid conditions and concomitant medications. During this phase, only unusual and rare ADRs are encountered. Hence, if we have a system which can help us determine any new information available in relation to their safety profile can be critically useful. And since there are considerable social and economic consequences of ADRs, there is a need to engage health-care professionals, in a well-structured program to build synergies for monitoring ADRs. ADR reporting is of prime importance in the success of any pharmacovigilance program.

Male preponderance of study population was seen in our study which corresponds with the study done by Pankaj $\mathrm{G}$ et $\mathrm{al} .{ }^{8}$ On contrary to our study, female preponderance was seen in another study performed by Subish $\mathrm{P}$ et al, in Nepal. ${ }^{9}$ We got a response rate of $64.70 \%$ in our study. This finding was in line with the finding of Khan SA et al, (response rate was 62.9\%) while it was $67.9 \%$ in a study done in Nepal., ${ }^{9,10}$ In contradiction to this very high response rate of $93.3 \%$ was present in a study done by Pimpalkhute SA et al. ${ }^{11}$ Similarly in a Nigerian study response rate of $82.5 \%$ was observed. ${ }^{12}$

Outcomes of our research, health-care professionals' practice toward ADR reporting was far below expectation. More alarming, however, is the fact that the interns, pharmacists and nursing staff have never reported a single case of ADR while working in the institution. 
Our results show that the awareness toward pharmacovigilance is $53.28 \%$ although the awareness towards reporting centers and reporting is only $6.12 \%$ comparing with the study of Madhan ramesh and Gurumurthy Parthasarathi in the year 2009 which is $89 \%$ and $41 \%$ respectively. ${ }^{13}$ It was noticed that the participants in our study could not utilize their knowledge to conduct proper ADR reporting since they had a lack of training in this regard. We found that only $21.35 \%$ health-care professionals were trained on how to report ADR. Similarly, a survey conducted in United Arab Emirates revealed that only $5.5 \%$ of doctors received training on ADR reporting. ${ }^{14}$ Furthermore, the majority of the respondents about $91.66 \%$ agreed that reporting of ADR is necessary and awareness that pharmacovigilance should be taught in detail to the health-care professionals. These findings were in accordance with findings of a study conducted by Gupta et al. ${ }^{15}$ Only $37.89 \%$ healthcare professionals knew the existence of PvPI. Whereas only few, i.e., $43.73 \%$ health-care professionals knew that in India the CDSCO is a regulatory body responsible for monitoring ADRs. These findings were lower compared to other studies conducted among the health-care professionals. In our study only $6.12 \%$ subjects reported ADR to the pharmacovigilance center as compare to $18.5 \%$ by Mala Kharkar and Suresh Bowalekar. ${ }^{16}$

Many Indian studies have indicated that there is a gradual increase in the knowledge and attitude of the health-care professionals toward pharmacovigilance, but unfortunately, it seems that the actual practice of ADR reporting is still deficient. Furthermore, in relation to ADR reporting, we also identified the various possible factors responsible for underreporting. These determinants of underreporting include no remuneration, difficulty in deciding whether ADR has occurred or not, lack of time, belief that a single unreported case may not affect ADR database, lack of training, and unawareness regarding the ADR reporting form etc. Similar factors were identified by studies conducted by Gupta et al. and Showande and Oyelola. ${ }^{17}$

Nwokike in his study suggested that attention should shift from spontaneous reporting by health-care workers to self-report or patient initiated reporting of ADRs; encouraging health-care professionals to self-report incidences of personal experiences of ADR may motivate them into engaging in pharmacovigilance activities after graduation. ${ }^{18}$

It has been reemphasized that there is a positive correlation between training of Pharmacovigilance and reporting ADR by health-care professionals Factors like the unawareness about the method to decide the causal relationship between the ADR can only be removed by regular training. ${ }^{19}$ The significance of adverse event monitoring and reporting can be increased through academic interference. This will ultimately help in improving the efficiency of pharmacovigilance program in India.
It has been advised that the health-care professionals; especially interns, pharmacists and nursing should be trained properly on ADR reporting to improve the current scenario in the pharmacovigilance program of the country. To improve the spontaneity in the reporting rates, the doctors suggested the organization of training programs (regular seminars/ workshops) and an uncomplicated reporting system with a quick feedback regarding their specific reports. Educational intervention could increase the physicians' awareness on ADRs and that the physicians would be able to incorporate the knowledge that they gained from their training into their everyday clinical practice.

\section{CONCLUSION}

The results of our study indicate that the acceptable number of health-care professionals had a good knowledge and attitude towards pharmacovigilance. There was a huge gap between the ADR experienced, and ADR reported by the health-care professionals. So, there is need of conductance of CMEs, workshops and seminars related to pharmacovigilance for all health care professionals especially nurses and pharmacists so, that whole community can be benefitted.

\section{Funding: No funding sources}

Conflict of interest: None declared

Ethical approval: The study was approved by the Institutional Ethics Committee

\section{REFERENCES}

1. Lazarou J, Pomeranz BH, Corey PN. Incidence of adverse drug reactions in hospitalized patients: A meta-analysis of prospective studies. JAMA 1998;279:1200-5.

2. Meyboom RH, Egberts AC, Gribnau FW, Hekster YA. Pharmacovigilance in perspective. Drug safety. 1999 Dec 1;21(6):429-47.

3. Hema N, Bhuvana K. Pharmacovigilance: The extent of awareness among the final year students, interns and postgraduates in a government teaching hospital. J Clin Diagn Res. 2012;6:1248-53.

4. Feely J, Moriarty S, O'Connor P. Stimulating reporting of adverse drug reactions by using a fee. BMJ. 1990;300:22-3.

5. World Health Organization. Safety of Medicines: A Guide to Detecting and Reporting Adverse Drug Reactions. Geneva: WHO/EDM/ QSM/2002.2; 2002.

6. Patil A, Gurav YA, Thorat MB, Walsangikar SD. Survey of pharmacovigilance awareness among healthcare professionals. Int $\mathrm{J}$ Pharmacol Ther. 2014;4:31-4.

7. Avery AJ, Anderson C, Bond CM. Evaluation of patient reporting of adverse drug reactions to the UK Yellow Card Scheme: literature review, descriptive and qualitative analyses, and questionnaire surveys. Health Technol Assess. 2011 May;15(20):1-234. 
8. Gupta P, Udupa A. Adverse Drug Reaction Reporting and Pharmacovigilance: Knowledge, Attitudes and Perceptions amongst Resident Doctors. J. Pharm. Sci. \& Res. 2011;3(2):1064-9.

9. Palaian S, Ibrahim M, Mishra P. Health professionals' knowledge, attitude and practices towards pharmacovigilance in Nepal. Pharm Pract (Granada). 2011 Oct-Dec;9(4):228-35.

10. Khan SA, Goyal C, Chandel N. Knowledge, attitudes, and practice of doctors to adverse drug reaction reporting in a teaching hospital in India: An observational study. J Nat Sc Biol Med. 2013;4:1916.

11. Pimpalkhute SA, Jaiswal KM, Sontakke SD. Evaluation of awareness about pharmacovigilance and adverse drug reaction monitoring in resident doctors of a tertiary care teaching hospital. Indian $\mathrm{J}$ Med Sci. 2012;66(3-4):55-61.

12. Oshikoya KA, Awobusuyi JO. Perceptions of doctors to adverse drug reaction reporting in a teaching hospital in Lagos, Nigeria. BMC Clin Pharmacol. 2009 Aug 11;9:14.

13. Ramesh M, Parthasarathi G. Adverse drug reaction reporting: the attitudes and the perceptions of the medical practitioners. Asian Journal of Pharmaceutical and Clinical Research. April-June 2009;2(2):10-14.

14. Wu WK, Pantaleo N. Evaluation of outpatient adverse drug reactions leading to hospitalization. Am J Health Syst Pharm. 2003;60:253-9.
15. Gupta SK, Nayak RP, Shivaranjani R, Vidyarthi SK. A questionnaire study on the knowledge, attitude, and the practice of pharmacovigilance among the healthcare professionals in a teaching hospital in South India. Perspect Clin Res. 2015;6:45-52.

16. Kharkar M, Bowalekar S. Knowledge, attitude and perception/practices (KAP) of medical practitioners in India towards adverse drug reaction (ADR) reporting Perspect Clin Res. 2012 Jul-Sep;3(3):90-4.

17. Showande JS, Oyelola FT. The concept of adverse drug reaction reporting: Awareness among pharmacy students in a Nigerian University. Internet $\mathbf{J}$ Med Update. 2013;8:24-30.

18. Nwokike J. Monitoring Adverse Drug Reaction in the Public Health Programs: The Case of the Nigeria TB Program; 2008. Available at: http://www.apps.who.int/medicinedocs/documents/s1 $8400 \mathrm{en} / \mathrm{s} 18400 \mathrm{en}$. pdf. [Last accessed on $2014 \mathrm{Nov}$ 19].

19. Remesh A. Identifying the reasons for under reporting of ADR: A cross sectional survey. Res J Pharm Biol Chem Sci. 2012;3:1379-86.

Cite this article as: Singh $\mathrm{K}$, Sayedda $\mathrm{K}$, Bhardwaj R, Yadav N, Quazi SA. A Study of awareness, attitude and practice of pharmacovigilance among health care professionals in a tertiary care teaching hospital in Bareilly, India. Int J Basic Clin Pharmacol 2017;6:1784-9. 